\title{
Searching for intermediates in Prins cyclisations: the 2-oxa-5-adamantyl carbocation $\dagger$
}

\author{
Roger W. Alder, ${ }^{* a}$ Fabrizio Carta, ${ }^{a}$ Christopher A. Reed, ${ }^{b}$ Irina Stoyanova ${ }^{b}$ and Christine L. Willis ${ }^{a}$ \\ Received 21st October 2009, Accepted 21st December 2009 \\ First published as an Advance Article on the web 28th January 2010 \\ DOI: $10.1039 / \mathbf{b 9 2 1 9 5 7 a}$
}

The 2-oxa-5-adamantyl carbocation 4 is shown to be a viable intermediate in several $\mathrm{S}_{\mathrm{N}} 1$ substitution reactions. However, attempts to observe the formation of $\mathbf{4}$ from various precursors by NMR methods (which succeed for the 1-adamantyl cation 5) failed, suggesting that $\mathbf{4}$ does not survive on longer timescales. DFT calculations suggest that the retro-Prins process ( $\beta$-cleavage, Grob fragmentation) to give enantiomeric $(1 R, 5 R)$ - and $(1 S, 5 S)$-7-methylene-2-oxoniabicyclo[3.3.1]non-2-ene cations 22 is the only realistic unimolecular escape route for 4 . With the $6-31 \mathrm{G}(\mathrm{d})$ basis set, B3LYP calculation predicts that $\mathbf{4}$ is only $11 \mathrm{~kJ} \mathrm{~mol}^{-1}$ more stable than $\mathbf{2 2}$, and the barrier separating $\mathbf{4}$ and $\mathbf{2 2}$ is calculated to be only $15 \mathrm{~kJ} \mathrm{~mol}^{-1}$, so rapid equilibration of these species is likely on the laboratory time scale. The implications of this study for the mechanism of the Prins cyclisation are discussed.

\section{Introduction}

Substituted tetrahydropyrans are common structural features of many natural products and biologically active compounds. A valuable approach for the synthesis of these heterocycles is the acidpromoted Prins-type cyclisation of an oxycarbenium ion generated in situ, for example, from reaction of a homoallylic alcohol with an aldehyde or from a homoallylic acetal, enol ether or $\alpha$-acetoxy ether. ${ }^{1-4}$ These stereoselective reactions have been used to good effect in the synthesis of a number of natural products. ${ }^{5-8}$ However, the mechanism of Prins cyclisations is not simple and there is good evidence for oxonia-Cope rearrangements and allyl transfer processes occurring under certain conditions. ${ }^{9-12}$ An in-depth understanding of the mechanisms involved is important to assist in the design of efficient strategies to complex targets. In 2002, Alder and co-workers proposed on the basis of DFT calculations ${ }^{13}$ that these reactions proceeded via a discrete carbocation intermediate 1 (Scheme 1).

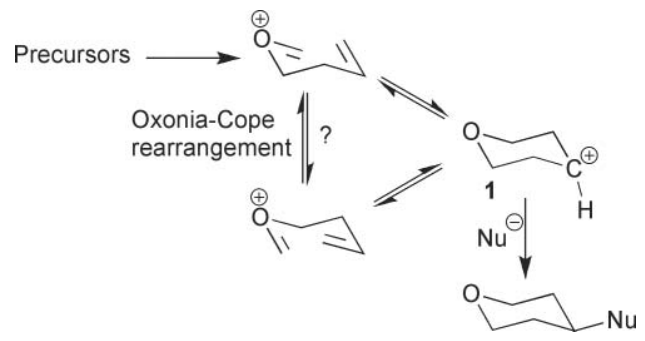

Scheme 1 Proposed mechanism for Prins cyclisations and oxonia-Cope rearrangements via the tetrahydro-2 $\mathrm{H}$-pyran-4-ylium cation $\mathbf{1}$.

${ }^{a}$ School of Chemistry, University of Bristol, Cantock's Close, Bristol, UK BS8 $1 T S$

${ }^{b}$ Department of Chemistry, University of California at Riverside, Riverside, CA, 92521, USA

$\dagger$ Electronic supplementary information (ESI) available: ${ }^{1} \mathrm{H}$ and ${ }^{13} \mathrm{C}$ NMR spectra for 5- $N$-(acetyl)-2-oxaadamantane 15. CCDC 752133. For ESI and crystallographic data in CIF or other electronic format see DOI: $10.1039 / \mathrm{b} 921957 \mathrm{a}$
These proposals have since received significant support from experimental work, ${ }^{14,15}$ but we hoped to obtain direct evidence for the existence of an intermediate related to $\mathbf{1}$, particularly because the DFT calculations predicted that $\mathbf{1}$ would show evidence of cyclic delocalisation (aromaticity), and unusual bond lengths. Carbocation 1 could also be an intermediate in the oxoniaCope rearrangements, which can accompany Prins cyclisations. Intermediates in pericyclic reactions are rare $^{16}$ so such species clearly deserve experimental study. This paper describes our studies to probe for a suitably-substituted tetrahydro- $2 \mathrm{H}$-pyran4-ylium cation.

\section{Results and discussion}

The parent tetrahydro- $2 H$-pyran-4-ylium carbocation $\mathbf{1}$ is not expected to possess unusual thermodynamic stability in spite of its delocalised nature, since potential aromaticity is only gained at the expense of the $\mathrm{CH}_{2}-\mathrm{CH}_{2}$ bond strength. The electronwithdrawing inductive (dipole) effect of the oxygen works against the conjugative effect and will also destabilise 1. B3LYP/6$311 \mathrm{G}(\mathrm{d})$ calculation of the formal equilibrium shown in eqn (1) predicts that this will lie marginally on the right-hand side $(\Delta E$ $-3 \mathrm{~kJ} \mathrm{~mol}^{-1}$ in the gas phase).

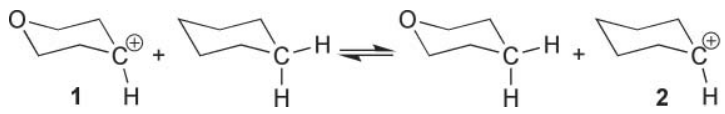

Tarbell and Hazen ${ }^{17}$ reported that the rate of solvolysis for 4-tetrahydropyranyl tosylate in acetic acid at $85{ }^{\circ} \mathrm{C}$ is only 0.027 that of cyclohexyl tosylate (they did not report on the products of solvolysis). While this is in qualitative agreement with the calculations for eqn (1), it is likely that the ability of the oxygen atom in 4-tetrahydropyranyl tosylate to donate electron density towards the developing carbocation centre is diminished by hydrogen bonding from the acetic acid solvent.

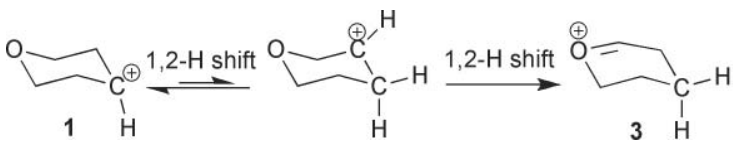


The cyclohexyl carbocation $\mathbf{2}$ has never been observed under stable ion conditions, because it rearranges too rapidly to the 1methylcyclopentyl cation. ${ }^{18}$ In the case of cation $\mathbf{1}$, we may expect that, in the absence of trapping nucleophiles, hydride shifts will lead rapidly to the tetrahydro- $2 \mathrm{H}$-pyran-2-ylium carbocation $\mathbf{3}$, eqn (2). Carbocation 3 is $112 \mathrm{~kJ} \mathrm{~mol}^{-1}$ more stable than $\mathbf{1}$ at the B3LYP/6-311G(d) level. Any substituted version of 1 where hydride shifts are possible is also likely to suffer the same fate.

These considerations led us to the adamantane skeleton, where hydride shifts are expected to have high barriers due to poor orbital overlap (see below) and our target cation became the 2-oxa-5adamantyl carbocation 4. B3LYP/6-311G(d) calculation of the position of the intermolecular hydride transfer reaction in eqn (3) shows that equilibrium lies just on the side of adamantane plus $4\left(\Delta E+1 \mathrm{~kJ} \mathrm{~mol}^{-1}\right)$, emphasising again that no special stability is associated with ions like $\mathbf{4}$. Nevertheless, carbocation $\mathbf{5}$ is readily generated under stable ion conditions, ${ }^{19,20}$ in spite of its bridgehead character, and one would expect that carbocation 4 might be generated under similar conditions.

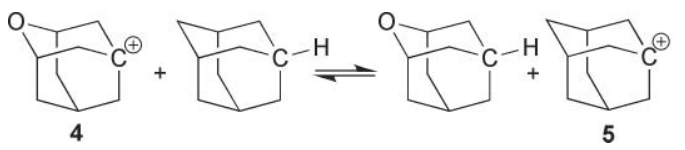

The oxaadamantane system possesses several other advantages for our study:

1. Preparation of 5-bromo-2-oxaadamantane 7 has been reported. ${ }^{21}$

2. The 2-oxa-1-adamantyl carbocation 6 (the counterpart of ion 3 ) is not stabilised by oxonium resonance (bridgehead $\pi$-bond) and is calculated to be less stable that ion $\mathbf{4}\left(\Delta E+9 \mathrm{~kJ} \mathrm{~mol}^{-1}\right)$ at the B3LYP/6-311G(d) level. Thus, even if 6 could be reached, e.g. via intermolecular hydride transfers, it should not predominate at equilibrium.

3. Since backside attack on $\mathbf{7}$ is impossible, any substitution reaction of 7 that results in a 5 -substituted 2-oxaadamantane product must have proceeded by an $\mathrm{S}_{\mathrm{N}} 1$ mechanism with $\mathbf{4}$ as the intermediate.
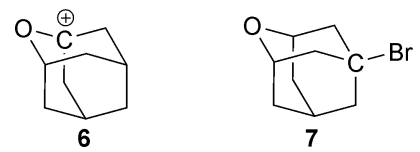

The substrate 5-bromo-2-oxaadamantane 7 was prepared using the four-step procedure shown in Scheme 2. Commercially available 2-adamantanone $\mathbf{8}$ was treated with methylmagnesium bromide to give 2-methyl-2-adamantanol $9 .{ }^{22,23}$ Krasutsky and coworkers have reported two methods for the fascinating conversion of tertiary alcohol 9 to 2-oxaadamantane $11 .{ }^{24,25} \mathrm{In}$ our hands, the two-step procedure proved to be the more efficient. Thus, alcohol 9 was first treated with TFAA- $\mathrm{H}_{2} \mathrm{O}_{2}$ at $-25^{\circ} \mathrm{C}$ to give, after workup, acetate 10 in $86 \%$ yield. On reaction with sulfuric acid, hydroxy acetate $\mathbf{1 0}$ readily cyclised to the required 2-oxaadamantane skeleton. The final step was a phase-transfer catalysed bromination of $\mathbf{1 1}^{\mathbf{2 1}}$ to give $\mathbf{7}$. We found that using a minimum amount of $50 \% \mathrm{NaOH}$ solution was crucial to the success of this reaction otherwise the corresponding 5-hydroxy-2-oxaadamantane 13 was isolated as the major product.

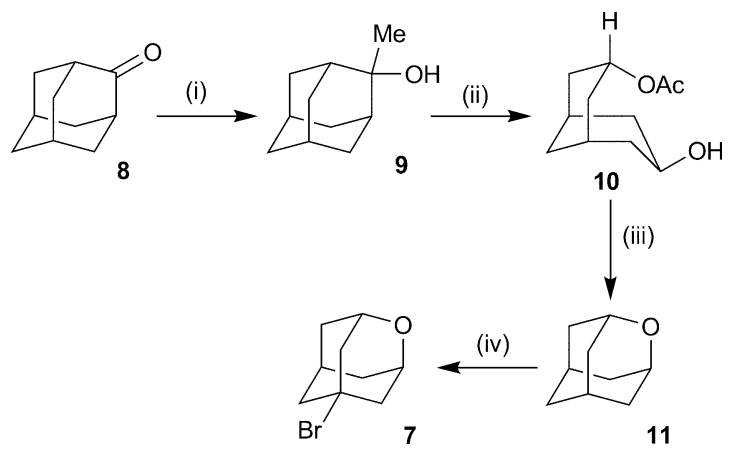

Scheme 2 Synthesis of 5-bromo-2-oxaadamantane 7. (i) $\mathrm{MeMgBr}_{2} \mathrm{Et}_{2} \mathrm{O}$, $96 \%$; (ii) TFAA, $\mathrm{H}_{2} \mathrm{O}_{2},-25^{\circ} \mathrm{C}, 86 \%$; (iii) $98 \% \mathrm{H}_{2} \mathrm{SO}_{4}, 98 \%$; (iv) $50 \% \mathrm{NaOH}$, $\mathrm{CBr}_{4}, \mathrm{BTEAC}, \mathrm{CH}_{2} \mathrm{Cl}_{2}, 40{ }^{\circ} \mathrm{C}, 39 \%$.

\section{Reactions of 5-bromo-2-oxaadamantane}

Initially, our aim was to gain evidence for the existence of an intermediate carbocation by conversion of 5-bromo-2-oxaadamantane 7 to other 5-substituted-2-oxadamantanes via $\mathrm{S}_{\mathrm{N}} 1$ reactions. Thus, bromide 7 was treated with $\mathrm{TMSN}_{3}$ and $\mathrm{SnCl}_{4}$ in dichloromethane at room temperature and the analogous azide $\mathbf{1 2}$ was isolated in $93 \%$ yield (Scheme 3). Furthermore, hydrolysis of 5-bromo2-oxaadamantane under a variety of conditions produced 2oxaadamantan-5-ol 13; $;^{26,27}$ no other products could be detected. These products were characterised by spectroscopic methods and their ${ }^{13} \mathrm{C}$ NMR data compared with calculated chemical shift values (Table 1). Thus, it is immediately clear that the 2-oxa-5adamantyl carbocation $\mathbf{4}$ is a real intermediate and is stable to ring opening and rearrangement on the time scale for displacement by azide or water.

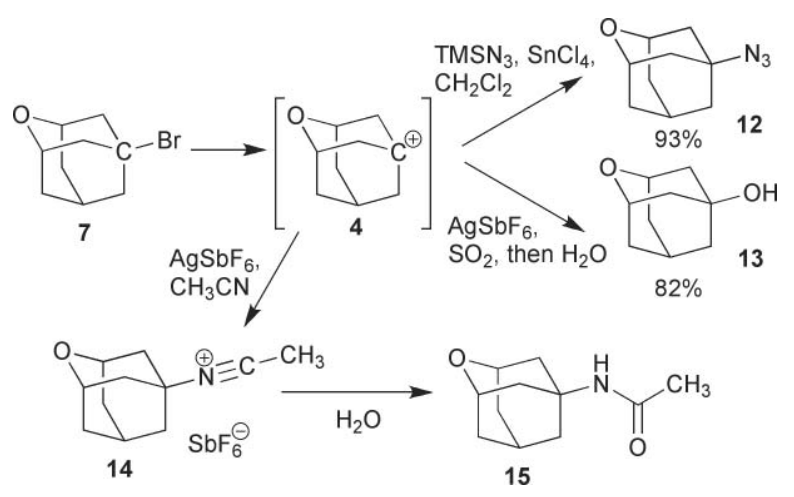

Scheme 3 Reactions involving the 2-oxa-5-adamantyl carbocation 4.

Next, in an attempt to observe cation 4 by ${ }^{13} \mathrm{C}$ NMR spectroscopy, 5-bromo-2-oxaadamantane 7 was reacted with $\mathrm{AgSbF}_{6}$ in dry acetonitrile under argon. This resulted in the clean production of nitrilium salt $\mathbf{1 4}$, which could be isolated as a white solid that was stable in the absence of moisture. The ${ }^{13} \mathrm{C}$ NMR spectrum of $\mathbf{1 4}$ revealed a downfield signal at $\delta_{\mathrm{C}} 176.5$ assigned to the quaternary carbon, $\mathrm{RN}^{+} \equiv C \mathrm{Me}$. As a guide for identifying possible ions and products in this and other reactions, we calculated NMR shifts for a number of species using the GIAO procedure at the B3LYP/6-31G(d) level in Spartan. In Table 1, calculated shifts are shown in italics, observed shifts 
Table 1 Observed and calculated ${ }^{a}{ }^{13} \mathrm{C}$ NMR shifts for 2-oxaadamantane derivatives

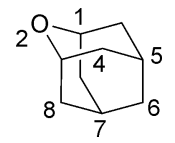

\begin{tabular}{llllllll}
\hline $\begin{array}{l}\text { Group at } \\
\text { position 2 }\end{array}$ & $\begin{array}{l}\text { Group at } \\
\text { position 5 }\end{array}$ & $\mathrm{C}-1$ & $\mathrm{C}-4$ & $\mathrm{C}-5$ & $\mathrm{C}-6$ & $\mathrm{C}-7$ & $\mathrm{C}-8$ \\
\hline $\mathrm{O}$ & $\mathrm{H}-\mathrm{C}$ & 69.4 & 36.2 & 26.9 & 35.9 & 26.9 & 36.2 \\
& & 67.6 & 36.7 & 29.8 & 36.7 & 29.8 & 36.7 \\
$\mathrm{HO}^{+}$ & $\mathrm{H}-\mathrm{C}$ & 90.7 & 34.2 & 24.4 & 33.2 & 24.4 & 34.2 \\
& & 100.0 & 34.6 & 26.8 & 33.4 & 26.4 & 36.0 \\
$\mathrm{O}$ & $\mathrm{Br}-\mathrm{C}$ & 71.7 & 47.8 & 62 & 47.5 & 30.2 & 34.2 \\
& & 70.1 & 52.5 & 68.7 & 51.4 & 37.6 & 39.0 \\
$\mathrm{HO}^{+}$ & $\mathrm{Br}-\mathrm{C}$ & 108.8 & 48.4 & 67.1 & 48.1 & 33.5 & 39.1 \\
$\mathrm{O}$ & $\mathrm{Cl}-\mathrm{C}$ & 69.0 & 47.5 & 71.9 & 47.6 & 32.6 & 36.4 \\
$\mathrm{HO}^{+}$ & $\mathrm{Cl}-\mathrm{C}$ & 86.6 & 45.5 & 56.8 & 44.4 & 28.9 & 34.9 \\
$\mathrm{O}$ & $\mathrm{HO}-\mathrm{C}$ & 70.4 & 44.2 & 67.0 & 43.6 & 28.5 & 34.6 \\
& & 70.0 & 45.8 & 65.8 & 45.8 & 30.6 & 35.7 \\
$\mathrm{HO}^{+}$ & $\mathrm{H}$ & & & & & & \\
& & 90.4 & 38.8 & 88.8 & 37.9 & 27.5 & 32.3 \\
$\mathrm{O}^{+}$ & $\mathrm{CH}$ & 86.3 & 38.9 & 87.6 & 40.5 & 30.3 & 34.1 \\
& & 68.6 & 38.7 & 57.2 & 37.9 & 27.2 & 34.0 \\
$\mathrm{O}^{+}$ & $\mathrm{C}^{+}$ & 67.1 & 40.6 & 65.7 & 40.2 & 29.4 & 33.4 \\
$\mathrm{H}_{2} \mathrm{O}^{+}-\mathrm{H} \cdots \mathrm{O}$ & $\mathrm{C}^{+}$ & 123.4 & 73.3 & 250.5 & 60.1 & 74.7 & 34.0 \\
$\mathrm{HO}^{+}$ & $\mathrm{C}^{+}$ & 117.8 & 65.7 & 282.4 & 72.7 & 90.4 & 34.3 \\
& & 129.9 & 58.9 & 290.4 & 83.1 & 98.7 & 35.2
\end{tabular}

${ }^{a}$ Calculated NMR shifts from the GIAO procedure at the B3LYP/6$31 \mathrm{G}(\mathrm{d})$ level in Spartan. Calculated shifts are shown in italics, observed shifts (where known) are in plain text.

(where known) are in plain text. For nitrilium salt 14, there is good agreement between observed and calculated shift for the ring carbon atoms. However the calculated shift for the sp carbon in the nitrilium ion is 101.6 , but the observed shift is $176.5 \mathrm{ppm}$. A similarly large discrepancy was found between observed (160) and calculated (103.4) shifts for the $\mathrm{CH}_{3}-\mathrm{C} \equiv \mathrm{N}^{+}-\mathrm{CH}_{3}$ nitrilium ion. We have no simple explanation, but note that the calculated B3LYP/6$31 \mathrm{G}(\mathrm{d})$ GIAO shift for the sp carbon atom in acetonitrile (102.7) is also significantly lower than the observed shift (117.7 ppm); for methyl isocyanide, the calculated (162.4) and observed shifts (157.5) are in better agreement. Agreement between calculated and observed shifts for these carbons might be improved by the inclusion of diffuse functions in the basis set used and the use triple zeta functions for the valence electrons, but we did not examine this. The nitrilium salt $\mathbf{1 4}$ was readily hydrolysed in quantitative yield to 5-acetamido-2-oxaadamantane $\mathbf{1 5}$ (Scheme 3). Again it is clear that cation 4 survives for long enough to react with the relatively weak nucleophile acetonitrile, admittedly present as the solvent.

While no sign of peaks which might be attributed to 4 were present in the NMR spectrum of nitrilium ion 14, we hoped that it might be in equilibrium with low concentrations of 4 . The salt 14 was therefore treated with excess $\mathrm{AgSbF}_{6}$ in dichloromethane in the knowledge that silver ions complex strongly with nitriles and so might remove any acetonitrile formed, but no changes could be detected. Salt 14 was also treated with $\mathrm{CH}_{3} \mathrm{OTf}$, which is known to react with free acetonitrile to form $\mathrm{MeC} \equiv \mathrm{N}-\mathrm{CH}_{3}{ }^{+},{ }^{28}$ but again no changes could be observed. Finally 14 was dissolved in $\mathrm{CD}_{3} \mathrm{C} \equiv \mathrm{N}$, and the NMR monitored for a week, but no exchange of $\mathrm{CH}_{3} \mathrm{C} \equiv \mathrm{N}$ and $\mathrm{CD}_{3} \mathrm{C} \equiv \mathrm{N}$ groups was observed.
Attempts to observe the 2-oxa-5-adamantyl carbocation 4 by NMR

Although it is clear that the 2-oxa-5-adamantyl carbocation 4 is behaving as a true intermediate in several reactions, observing it under stable ion conditions has proved elusive. Prior to embarking on these studies, we deemed it prudent to confirm our experimental techniques by ensuring that we could indeed generate and observe the known 1-adamantyl carbocation 5. ${ }^{19,20}$ We experienced no difficulties in observing clean generation of $\mathbf{5}\left(\delta_{\mathrm{C}} 302\right)$ by either reaction of commercially available 1 -adamantanol with magic acid $\left(4: 1 \mathrm{HSO}_{3} \mathrm{~F}: \mathrm{SbF}_{5}\right)$, or from 1-bromoadamantane through reaction with $\mathrm{SbF}_{5}$ in liquid $\mathrm{SO}_{2}$ (Scheme 4).

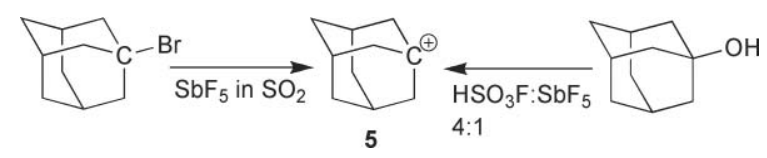

Scheme 4 Generation of the 1-adamantyl carbocation 5.

Similar transformations on the 2-oxa-5-adamantyl analogues were then investigated. First, reaction of 2-oxaadamantan-5-ol 13 with excess magic acid $(4: 1)$ at $-80{ }^{\circ} \mathrm{C}$ produced a clean ${ }^{13} \mathrm{C}$ NMR spectrum of a species which was clearly not a carbocation (no resonance below $\delta 100 \mathrm{ppm}$ ). We assign the spectrum to the diprotonated species 16 (Scheme 5) although $\mathrm{SbF}_{5}$ adducts in place of protons cannot be ruled out. In particular the resonances at 90.4 and $88.8 \mathrm{ppm}$ are in satisfactory agreement with those predicted at 86.3 and 87.6 in the calculated spectrum (Table 1). Unfortunately, careful warming of the solution did not lead to the formation of 4; the ${ }^{13} \mathrm{C}$ NMR which resulted indicated that a complex mixture of products was formed.

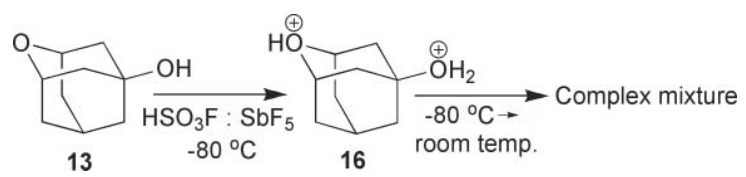

Scheme 5 Protonation of 2-oxaadamantan-5-ol 13.

Reaction of 5-bromo-2-oxaadamantane 7 with $\mathrm{SbF}_{5}$ in liquid $\mathrm{SO}_{2}$ also did not lead to the formation of 4; a complex ${ }^{13} \mathrm{C} \mathrm{NMR}$ spectrum resulted at $-80{ }^{\circ} \mathrm{C}$. We had anticipated difficulties with reaction of bromide 7 with Lewis acids, since the oxygen atom provides an alternative basic site, and once this is complexed, there is expected to be less opportunity for ionisation of the bromide.

We had hoped that silver ion would discriminate in favour of bromide removal, but reaction of 7 with $\mathrm{AgSbF}_{6}$ in liquid $\mathrm{SO}_{2}$ only resulted in the formation of the hydrolysis product 2oxaadamantan-5-ol 13, in spite of extensive efforts to ensure that the reactants and solvent were dry. It is worth noting that, in these experiments, no protic or Lewis acid is present to convert any adventitious water to non-nucleophilic $\mathrm{H}_{3} \mathrm{O}^{+}$.

In addition to $\mathrm{AgSbF}_{6}$, silver carboranes were investigated as potential halide abstraction reagents because the exceptional inertness of carborane anions makes them especially useful in stabilising tertiary carbocations. The t-butyl cation is stable at room temperature as a carborane salt and amenable to $\mathrm{X}$ ray crystallographic characterisation. ${ }^{29}$ Compared to $\mathrm{SbF}_{6}{ }^{-}$and related oxy- and fluoroanions, icosahedral carborane anions of the type $\mathrm{CHB}_{11} \mathrm{R}_{5} \mathrm{X}_{6}{ }^{-}(\mathrm{R}=\mathrm{H}, \mathrm{Me}, \mathrm{X} ; \mathrm{X}=$ halide $)$ have lower 
nucleophilicity and this can lead to different outcomes in halide metathesis reactions. ${ }^{30}$ Counterintuitively, the electrophilicity of $\mathrm{Ag}^{+}$is diminished as a carborane salt because the halide metathesis reaction is arrested at a halide-bridged intermediate stage. Intermediates of the type substrate-X-Ag(carborane) can frequently be observed. ${ }^{31}$ This appears to be the case with 5bromo-2-oxaadamantane as substrate because treatment of 7 with $\mathrm{Ag}\left(\mathrm{CHB}_{11} \mathrm{H}_{6} \mathrm{Br}_{6}\right)$ in dichloromethane produces a white precipitate whose IR spectrum as a $\mathrm{KBr}$ pellet is consistent with $1: 1$ adduct formation and a supernatant whose ${ }^{13} \mathrm{C} N M R$ in $\mathrm{CD}_{2} \mathrm{Cl}_{2}$ indicates a mildly perturbed substrate $(67.1,62.9,38.8,38.4,32.5,25.9 \mathrm{ppm})$ alongside peaks from the starting material $(70.7,63.4,47.1,46.5$, 33.3 and $29.6 \mathrm{ppm}$ ). The presence of acetonitrile, expected to give the nitrilium cation $\mathbf{1 4}$ if the desired cation $\mathbf{4}$ is accessible, had no effect on the outcome of this reaction confirming that the metathesis reaction was indeed stalled. Thus, a stronger halide abstracting reagent than $\mathrm{Ag}^{+}$is required if we are to take advantage of carboranes as inert counterions.

We therefore turned our attention to trialkylsilylium carborane reagents, $\mathrm{R}_{3} \mathrm{Si}$ (carborane), which are much superior as halide abstractors compared to silver. ${ }^{32}$ Treatment of 5-bromo2-oxaadamantane 7 with 1 equiv. of $\mathrm{Et}_{3} \mathrm{Si}\left(\mathrm{CHB}_{11} \mathrm{H}_{5} \mathrm{Br}_{6}\right)$ in $o$ dichlorobenzene- $d_{4}$ gave a new product whose ${ }^{1} \mathrm{H}$ NMR spectrum is consistent not with halide abstraction, but with silylation at the ether $\mathrm{O}$ atom, forming the oxonium ion 17 (Scheme 6). Consistent with cationic character, nearly all of the ${ }^{1} \mathrm{H}$ resonances of the product $(4.97,2.55-1.83 \mathrm{ppm})$ are downfield of the starting material $(4.16,2.63-1.61 \mathrm{ppm})$. In particular, the downfield resonance ascribed to the $\mathrm{C} 1$ proton adjacent to the oxonium centre (4.16 ppm in 7) experiences the largest downfield shift. Addition of a second equivalent of $\mathrm{R}_{3} \mathrm{Si}\left(\mathrm{CHB}_{11} \mathrm{H}_{5} \mathrm{Br}_{6}\right)$ to this product had no detectable effect in the ${ }^{1} \mathrm{H}$ NMR spectrum, suggesting that the positive charge on $\mathbf{1 7}$ inhibits reaction of the silyl electrophile at $\mathrm{Br}$, preventing the desired bromide abstraction.

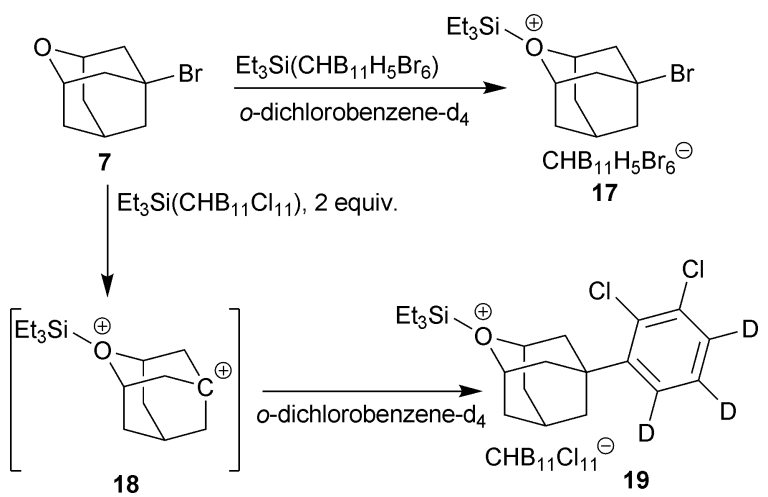

Scheme 6 Reactions of 5-bromo-2-oxaadamantane with trialkylsilylium carborane reagents.

However, when the electrophilicity of the silylium carborane reagent was increased by using the less nucleophilic $\mathrm{CHB}_{11} \mathrm{Cl}_{11}-$ anion in place of $\mathrm{CHB}_{11} \mathrm{H}_{5} \mathrm{Br}_{6}^{-}$, reaction of 7 with two equivalents of $\mathrm{Et}_{3} \mathrm{Si}\left(\mathrm{CHB}_{11} \mathrm{Cl}_{11}\right)$ in $o$-dichlorobenzene- $d_{4}$ did occur. As expected, ${ }^{1} \mathrm{H}$ NMR indicated that the first equivalent silylated 7 at $\mathrm{O}$ to form cation 17. The second silylium equivalent produced further changes in the aliphatic region of the ${ }^{1} \mathrm{H}$ NMR spectrum but without obvious interpretation. Fortunately, crystals of the product suitable for X-ray analysis were obtained (CCDC 752133) and shown to have the 5-bromo group of cation $\mathbf{1 7}$ replaced by an $o$-dichlorophenyl group (Fig. 1). This result can be understood in terms of silyl abstraction of $\mathrm{Br}$ from $\mathbf{1 7}$ to form dication $\mathbf{1 8}$ followed by electrophilic attack on the $o$-dichlorobenzene solvent to form 19 (Scheme 6). Due to its overall dipositive charge, dication 18 is expected to be more reactive than the desired carbocation 4 so reaction of this intermediate with solvent is not surprising.

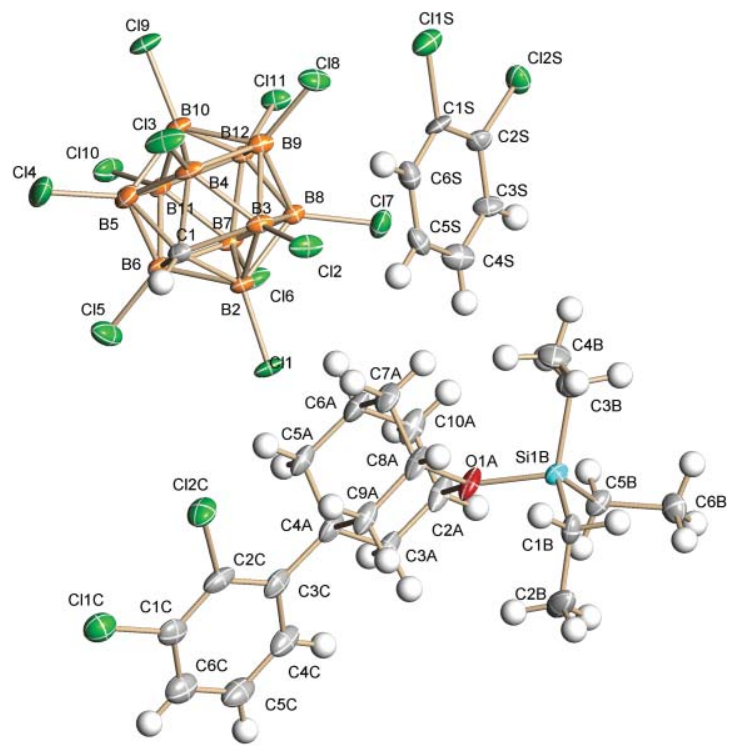

Fig. 1 X-Ray structure of 19.

Further evidence for the formation of a reactive dication $\mathbf{1 8}$ comes from the observation that when the same reaction is performed in the presence of hexane, crystals of the 2-methylpentyl carbocation salt were isolated and characterised by single crystal $\mathrm{X}$-ray analysis. This cation has been previously isolated and characterised by X-ray analysis by reacting hexanes with the highly electrophilic $\mathrm{CH}_{3}$ (carborane) derivatives. ${ }^{29}$ Hydride abstraction from $n$-hexane is presumed to occur forming the primary hexyl carbocation which rapidly rearranges via 1,2 Meerwein shifts to the more stable tertiary 2-methylpentyl cation. ${ }^{29}$ Evidently, a highly reactive carbocation must be formed in the reaction of 2 equiv. of $\mathrm{Et}_{3} \mathrm{Si}\left(\mathrm{CHB}_{11} \mathrm{Cl}_{11}\right)$ with 7 and it is reasonable to assign this role to dication $\mathbf{1 8}$, a more electrophilically activated analogue of the desired cation 4 .

In summary, various reasonable ways to generate cation $\mathbf{4}$ failed to produce NMR spectroscopic evidence for its existence on an extended time scale, and in the next section we explore possible reasons for this.

\section{Potential fates for the 2-oxa-5-adamantyl carbocation}

In principle, cation $4\left(\mathrm{C}_{2}\right.$ symmetry) can undergo six unimolecular rearrangements: two 1,2-hydrogen shifts, two 1,2-carbon shifts, and two $\beta$-cleavages. As mentioned in the introduction, 1,2hydrogen shifts in the adamantane system are expected to have high barriers due to poor orbital overlap. We located the transition state for the rearrangement pathway leading to ion 20 (see Scheme 7). This lies $266 \mathrm{~kJ} \mathrm{~mol}^{-1}$ above 4 at the B3LYP/6-31G(d) level; the enormous barrier certainly rules out this intramolecular 
Table 2 B3LYP/6-31G(d) energies relative to 2-oxa-5-adamantyl carbocation $4\left(\mathrm{~kJ} \mathrm{~mol}^{-1}\right)$

\begin{tabular}{ll}
\hline & $\Delta E, \mathrm{~kJ} \mathrm{~mol}^{-1}$ \\
\hline $\mathbf{6}$ & 10.1 \\
Prins cyclisation TS & 15.2 \\
$\mathbf{2 2}$ & 11.3 \\
$\mathbf{2 2}$ & -25.6 \\
TS for H-shift to give & 265.7 \\
$\mathbf{2 0}$ & \\
\hline
\end{tabular}

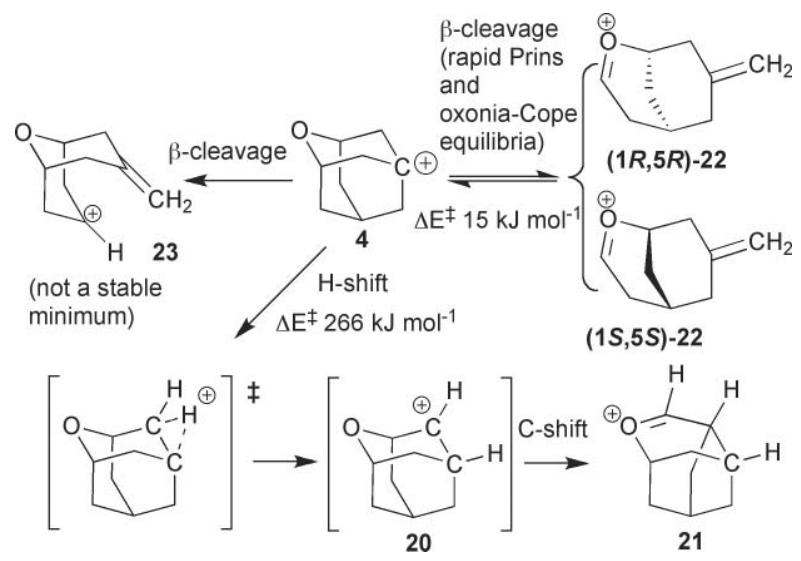

Scheme 7 Potential fates of the 2-oxa-5-adamantyl carbocation 4. At the B3LYP/6-31G(d) level, 21 is $26 \mathrm{~kJ} \mathrm{~mol}^{-1}$ more stable than 4, 22 is $11 \mathrm{~kJ} \mathrm{~mol}^{-1}$ less stable, and 23 is about $100 \mathrm{~kJ} \mathrm{~mol}^{-1}$ less stable, but is not a minimum.

hydrogen shift, and this is surely also true for the alternative shift. Actually ion $\mathbf{2 0}$ itself does not appear to exist but rearranges without a further barrier to give oxonium ion $\mathbf{2 1}$, containing the tricyclo[4.3.1.03,8]decane (protoadamantane) skeleton, which the calculations indicate is the most stable ion in the whole system (Table 2).

The 1,2-carbon shifts lead to primary carbocations that would be expected to undergo rapid $\beta$-cleavage to give the same ions as derived from 4 itself by $\beta$-cleavages. Thus, the two possible $\beta$-cleavages shown in Scheme 7 are the only likely unimolecular reaction pathways. The retro-Prins process to give enantiomeric $(1 R, 5 R)$ - and $(1 S, 5 S)$-7-methylene-2-oxonia-bicyclo[3.3.1]non-2ene cations 22 is discussed in more detail below. Surprisingly, the alternative $\beta$-cleavage does not lead to a stable minimum at the B3LYP/6-31G(d) level. The classical structure corresponding to 23 (Scheme 6) lies about $100 \mathrm{~kJ} \mathrm{~mol}^{-1}$ above that for $\mathbf{4}$, but the energy continues to rise as the alkene and the carbocation centre are driven further apart.

Computational estimates for the retro-Prins 4/22 equilibrium and reaction barrier vary somewhat with computational method and basis set, but all the indications are that this offers a very easy escape route for 4. B3LYP/6-31G(d) calculations clearly favour the closed ion $4, \Delta E 11 \mathrm{~kJ} \mathrm{~mol}^{-1}$ with an activation energy for ring opening of $15 \mathrm{~kJ} \mathrm{~mol}^{-1}$ (see Table 2). With the larger 6-311G(d) basis set, $\Delta E$ is reduced to $3 \mathrm{~kJ} \mathrm{~mol}^{-1}$ and $\Delta E^{\ddagger}$ comes down to $12 \mathrm{~kJ} \mathrm{~mol}^{-1}$. The $\mathrm{mPW} 1 \mathrm{~K}$ functional, ${ }^{33}$ often recommended for transition states fails to find the ions 22 to be stable minima (i.e. the situation is similar to that for 23), and this is also the situation predicted by Grimme's spin-component-scaled modification of
MP2 ${ }^{34-36}$ Finally the G3(MP2) procedure, normally considered to be reliable to $10 \mathrm{~kJ} \mathrm{~mol}^{-1}$, favours the closed ion 4 by $14 \mathrm{~kJ} \mathrm{~mol}^{-1}$.

In spite of these uncertainties, the general conclusion must be that $\mathbf{4}$ and $\mathbf{2 2}$ are likely to be in equilibrium on any but the very shortest timescales. The observation of clean $S_{N} 1$ reactions via 4 under neutral or weakly acidic conditions may be due to either:

1. Reactions occuring on a shorter timescale than required to establish the $\mathbf{4 / 2 2}$ equilibrium.

2. The $4 / 22$ equilibrium lying sufficiently far on the side of 4, that products from 22 are not detected (a $\Delta E$ of $10 \mathrm{~kJ} \mathrm{~mol}^{-1}$ corresponds to $1-2 \%$ of products from 22 being formed.

Our present evidence does not allow a decision between these possibilities and it is unlikely that further computational studies will provide a satisfactory answer. Under sufficiently gentle ionising conditions, the $\mathbf{4} / \mathbf{2 2}$ equilibrium might be observable, and we are still seeking to achieve this. However the bicyclic cation 22 is undoubtedly capable of reacting further in various ways under strongly acidic conditions (Scheme 8).

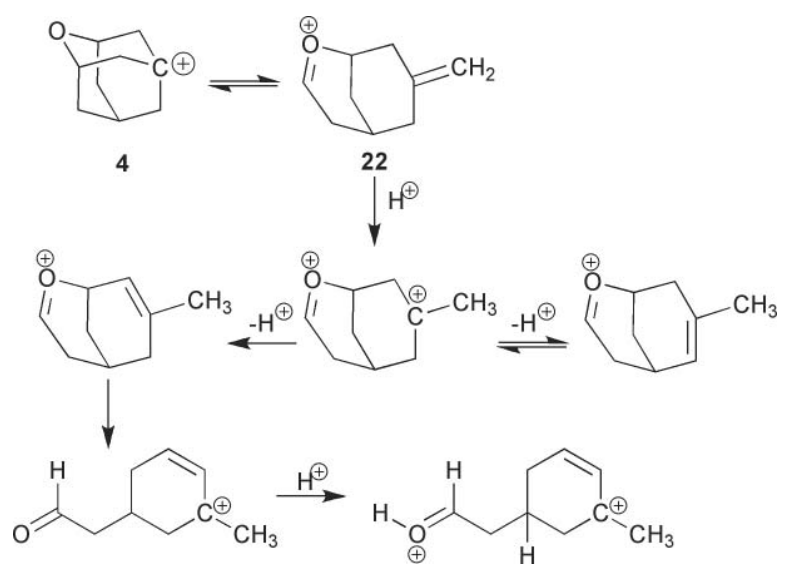

Scheme 8 Potential protonation and ring opening reactions of 22.

\section{Conclusions and implications for the mechanism of Prins cyclisations}

We have shown that the 2-oxa-5-adamantyl carbocation 4 is a viable intermediate in several $\mathrm{S}_{\mathrm{N}} 1$ substitution reactions. However, all attempts to date to observe it directly by NMR have failed. Although this is disappointing, we believe that the present evidence concerning 4 lends support to the proposal that 4-oxacyclohexyl carbocations related to $\mathbf{1}$ are intermediates in Prins cyclisation reactions and oxonia-Cope rearrangements.

\section{Experimental}

\section{General procedures and solvent purification}

${ }^{1} \mathrm{H}$ and ${ }^{13} \mathrm{C}$ NMR spectra were recorded using a Jeol Delta/GX $270 \mathrm{MHz}$, Jeol Delta/GX $400 \mathrm{MHz}$, Jeol Eclipse $300 \mathrm{MHz}$, Jeol Eclipse $400 \mathrm{MHz}$ and Alpha $500 \mathrm{MHz}$ spectrometers in deuterated chloroform unless otherwise stated using tetramethylsilane (TMS) as internal reference. Chemical shifts are reported in parts per million (ppm), and coupling constants $(J)$ are in $\operatorname{Hertz}(\mathrm{Hz})$. NMR tubes fitted with PTFE valves manufactured by J. Young (Scientific 
Glassware) Ltd. were used for experiments using sulfur dioxide and were stored at r.t. under argon.

Infrared spectra were recorded on either a Perkin Elmer 881 spectrometer or Perkin Elmer Spectrum One FT-IR spectrometer as neat solution, solids or films on sodium chloride plates.

Mass spectra, both high (HR) and low resolution (LR), were recorded on VG Micromass 3DS/2RS MS9 double focusing mass spectrometer and were obtained using electron ionisation (EI), chemical ionisation (CI) or electrospray (ESI) techniques.

Melting points (m.p.) were measured in open capillary tubes, unless otherwise stated, using a Gallenkamp melting point apparatus and are uncorrected.

Thin layer chromatography (TLC) was carried out on Merck silica gel 60 F254 aluminium backed plates. Visualisation was achieved with UV light at $254 \mathrm{~nm}$ or by dipping into a $0.5 \%$ aqueous potassium permanganate solution, by Hanessian's stain solution and heating with a hot air gun or by exposure to iodine.

Flash column chromatography was carried out using silica gel (obtained from Fluorochem Ltd.) as the adsorbent according to the procedure of Still et al. ${ }^{37}$ The crude product was introduced into the column as a solution in the same elution solvent system, as a powder obtained by mixing the crude product with the same weight of silica gel in acetone and solvent was removed in vacuo at room temperature or dissolved into the minimum amount of dichloromethane (DCM).

All moisture or air sensitive reactions were carried out in ovendried glassware under a positive pressure of nitrogen or argon using standard syringe/septa techniques.

Dry tetrahydrofuran (THF), DCM, toluene, diethyl ether and acetonitrile were obtained by passing through a modified Grubbs system of alumina columns, manufactured by Anhydrous Engineering. Hexanes were purified by distillation from $4 \AA$ molecular sieves under reduced pressure. KSF clay and K-10 montmorillonite clay were activated by storing in oven at $120{ }^{\circ} \mathrm{C}$ overnight.

Sulfur dioxide was purchased from Aldrich Chemical Co. and used after passing through sulfuric acid traps combined with phosphorus pentoxide columns. Alternatively, it was distilled from phosphorus pentoxide at $-12{ }^{\circ} \mathrm{C}$ under normal pressure. All the inert gases used (nitrogen or argon) were passed through phosphorus pentoxide in jacket columns.

Magnesium for Grignard reactions was crushed in a mortar before use, washed with diethyl ether, dried in an oven at $120{ }^{\circ} \mathrm{C}$ for $24 \mathrm{~h}$ and then stored under vacuo at r.t.

Silver hexafluoroantimonate, silver tetrafluoroborate, 1-bromoadamantane, 5-bromo-2-oxaadamantane, 1-azidoadamantane and 5-azido-2-oxaadamantane were stored under nitrogen or argon before use. $\mathrm{Ag}\left(\mathrm{CHB}_{11} \mathrm{H}_{6} \mathrm{Br}_{6}\right),{ }^{38} \mathrm{Et}_{3} \mathrm{Si}\left(\mathrm{CHB}_{11} \mathrm{H}_{6} \mathrm{Br}_{6}\right)^{38}$ and $\mathrm{Et}_{3} \mathrm{Si}\left(\mathrm{CHB}_{11} \mathrm{Cl}_{11}\right)^{32}$ were prepared as previously described and handled in a Vacuum Atmospheres Corp. glovebox with $\mathrm{H}_{2} \mathrm{O}$, $\mathrm{O}_{2}<1$ ppm. Commercial $o$-dichlorobenzene- $d_{6}$ was dried over $4 \AA$ molecular sieves.

All other solvents and chemicals were used as supplied from Aldrich Chemical Co., Acros, Fisher, Alfa Aesar or Lancaster Synthesis.

\section{2-Hydroxy-2-methyl-adamantane 9}

Adamantan-2-one 8 (6.0 g, $1.0 \mathrm{eq})$ in dry diethyl ether $(70 \mathrm{ml})$ was added dropwise to a fresh prepared solution of methyl magnesium iodide in dry diethyl ether. The mixture was stirred at r.t. for $1.5 \mathrm{~h}$ under a nitrogen atmosphere and then quenched with a saturated aqueous ammonium chloride solution $(70 \mathrm{ml})$. The mixture was extracted with diethyl ether $(3 \times 30 \mathrm{ml})$ and the combined organic layers washed with a saturated aqueous sodium hydrogen carbonate solution $(3 \times 30 \mathrm{ml})$, dried over magnesium sulfate, filtered and concentrated in vacuo to give a white solid compound that was purified by silica gel column chromatography eluting with $25 \%$ ethyl acetate in n-hexane to give $\mathbf{9}$ as a crystalline solid m.p. $207{ }^{\circ} \mathrm{C}$ (lit $\left.{ }^{22} 207.8-209.0{ }^{\circ} \mathrm{C}\right)(6.38 \mathrm{~g}, 96 \%$ yield $) . \delta_{\mathrm{H}}$ $\left(400 \mathrm{MHz}, \mathrm{CDCl}_{3}\right) 1.33-2.20(17 \mathrm{H}, \mathrm{m}) ; \delta_{\mathrm{C}}\left(100 \mathrm{MHz}, \mathrm{CDCl}_{3}\right)$ 27.4, $27.5\left(\mathrm{CH}_{3}\right), 29.3,33.0,35.1,38.3,39.1$ and 73.7.

\section{Double Criegee rearrangement on 2-hydroxy-2-methyl adamantane $9^{24}$}

A solution of trifluoroacetic anhydride (108.8 g, $43.5 \mathrm{eq})$ and $50 \%$ aqueous hydrogen peroxide $(11.8 \mathrm{~g}, 15.0 \mathrm{eq})$ was prepared at $-25^{\circ} \mathrm{C}$ and the solution stirred for $30 \mathrm{~min}$ at the same temperature. Then 2-hydroxy-2-methyl adamantane 9 (2.0 g, $1.0 \mathrm{eq})$ was added in 4 portions and the reaction stirred at $-20^{\circ} \mathrm{C}$ for $2.5 \mathrm{~h}$. The reaction was quenched by slow addition of water $(100 \mathrm{ml})$ keeping the temperature below $-30{ }^{\circ} \mathrm{C}$ and then stirred for $10 \mathrm{~min}$ at r.t. The solution was extracted with dichloromethane $(3 \times 30 \mathrm{ml})$ and the combined organic layers washed with water $(3 \times 20 \mathrm{ml})$, saturated aqueous solution of sodium sulfite $(3 \times 30 \mathrm{ml})$ and water $(3 \times$ $30 \mathrm{ml})$. A small amount of the above solution $(0.2 \mathrm{ml})$ was tested for peroxides and then, if test is negative, the mother solution was dried over magnesium sulfate, filtered and solvent evaporated in vacuo to give a white solid compound that was crystallised from n-hexane to afford 7-hydroxybicyclo[3.3.1]nonan-3-yl acetate $\mathbf{1 0}$ $(1.70 \mathrm{~g}, 86 \%$ yield $) \delta_{\mathrm{H}}\left(400 \mathrm{MHz}, \mathrm{CDCl}_{3}\right) 1.34(1 \mathrm{H}, \mathrm{m}), 1.54(1 \mathrm{H}$, m) 1.72-2.24 (14H, m), $4.04(1 \mathrm{H}, \mathrm{tt}, J 7.4,6.5), 5.13(1 \mathrm{H}, \mathrm{q}, J 5.3)$; $\delta_{\mathrm{C}}\left(100 \mathrm{MHz}, \mathrm{CDCl}_{3}\right) 21.6\left(\mathrm{CH}_{3}\right), 24.5,27.7,36.2,36.7,65.9,69.6$ and $170.2(\mathrm{C}=\mathrm{O})$.

\section{Synthesis of 2-oxaadamantane 11}

Concentrated sulfuric acid $(50 \mathrm{ml})$ was cooled at $-10{ }^{\circ} \mathrm{C}$ then hydroxyacetate $\mathbf{1 0}(1.0 \mathrm{~g})$ was added all at once and the mixture was vigorously stirred at the same temperature for $1 \mathrm{~h}$. The reaction was poured into ice and extracted with dichloromethane $(3 \times$ $15 \mathrm{ml}$ ). The combined organic layers were washed with $5 \%$ aqueous solution of sodium hydrogen carbonate $(3 \times 20 \mathrm{ml})$, dried over magnesium sulfate, filtered and evaporation of solvent in vacuo gave a white solid compound which was purified by sublimation (bath temperature $80^{\circ} \mathrm{C}, 10 \mathrm{~mm} \mathrm{Hg}$ ) to afford 2-oxaadamantane 11 as a crystalline solid product $(0.68 \mathrm{~g}, 98 \%$ yield $)$ m.p. $224{ }^{\circ} \mathrm{C}$ (sealed tube), lit. ${ }^{39}$ m.p. $226-229^{\circ} \mathrm{C} ; \delta_{\mathrm{H}}\left(400 \mathrm{MHz}, \mathrm{CDCl}_{3}\right) 1.66$ $(4 \mathrm{H}, \mathrm{d}, J 9.0), 1.90(2 \mathrm{H}, \mathrm{s}) 2.06-2.09(6 \mathrm{H}, \mathrm{m}), 4.01(2 \mathrm{H}, \mathrm{m}) ; \delta_{\mathrm{C}}$ $\left(100 \mathrm{MHz}, \mathrm{CDCl}_{3}\right)$ 26.6, 35.8, 36.3 and 68.1.

\section{Double Criegee rearrangement on 2-hydroxy-2-methyladamantane 9 and cyclisation (one-pot reaction)}

A solution of trifluoroacetic anhydride (108.8 g, $43.5 \mathrm{eq})$ and $50 \%$ aqueous hydrogen peroxide $(11.8 \mathrm{~g}, 15.0 \mathrm{eq})$ was prepared at $-25^{\circ} \mathrm{C}$ and the solution stirred for $30 \mathrm{~min}$ at the same temperature. Then 2-hydroxy-2-methyladamantane 9 ( $2.0 \mathrm{~g}, 1.0 \mathrm{eq})$ was added in 4 portions and the reaction stirred at $-15-20{ }^{\circ} \mathrm{C}$ for $2.5 \mathrm{~h}$. The 
reaction was quenched by slow addition of water $(100 \mathrm{ml})$ keeping the temperature below $-30{ }^{\circ} \mathrm{C}$ and then it was stirred for $24 \mathrm{~h}$ at r.t. The solution was extracted with dichloromethane $(3 \times 50 \mathrm{ml})$ and the combined organic layers washed with water $(3 \times 30 \mathrm{ml})$, saturated aqueous solution of sodium sulfite $(3 \times 30 \mathrm{ml})$, water $(3 \times$ $30 \mathrm{ml})$. A small amount of the above solution $(0.2 \mathrm{ml})$ was tested for peroxides and if the test was negative the mother solution was dried over magnesium sulfate, filtered and evaporated to dryness to give a white solid compound which was purified by sublimation (bath temperature $80{ }^{\circ} \mathrm{C}, 10 \mathrm{~mm} \mathrm{Hg}$ ) to afford 2-oxaadamantane 11 as a crystalline solid product $(0.91 \mathrm{~g}, 55 \%)$.

\section{5-Bromo-2-oxaadamantane 7}

A solution of $50 \%$ sodium hydroxide in water $(0.5 \mathrm{ml})$ was added to a solution of 2-oxaadamantane 11 (1.35 g. 1.0 eq), benzyltrimethylammonium chloride $(0.13 \mathrm{~g}, 20 \mathrm{~mol} \%)$ and carbon tetrabromide $(1.05 \mathrm{~g}, 1.1 \mathrm{eq})$ in dichloromethane $(38 \mathrm{ml})$. The mixture was vigorously stirred at $40{ }^{\circ} \mathrm{C}$ for $90 \mathrm{~h}$. The reaction was cooled at r.t., diluted with water $(100 \mathrm{ml})$, filtered thought Celite ${ }^{\circledR}$ and extracted with dichloromethane $(7 \times 30 \mathrm{ml})$. The combined organic layers were dried over magnesium sulfate, filtered and solvent removed in vacuo to give a waxy solid product that was purified by sublimation in vacuo (bath temperature $80{ }^{\circ} \mathrm{C}, 10 \mathrm{~mm} \mathrm{Hg}$ ) to remove starting material and the residue obtained by silica gel column chromatography eluting with $70 \%$ dichloromethane in n-hexane to afford 5-bromo-2-oxaadamantane 7 as a white solid: m.p. 47$48{ }^{\circ} \mathrm{C} ; \delta_{\mathrm{H}}\left(400 \mathrm{MHz}, \mathrm{CDCl}_{3}\right) 1.63(2 \mathrm{H}, \mathrm{d}, J 12.4), 2.06(2 \mathrm{H}, \mathrm{d}, J$ 12.4), 2.32 (3H, d, $J 11.9), 2.50$ (2H, s), 2.63 (2H, d, $J 11.9), 4.16$ $(2 \mathrm{H}, \mathrm{s}) ; \delta_{\mathrm{C}}\left(100 \mathrm{MHz}, \mathrm{CDCl}_{3}\right) 30.3,34.4,47.6,48.0,61.7$ and 71.3 .

\section{5-Azido-2-oxaadamantane 12}

Tin(IV) chloride (0.22 g, 1.8 equiv.) was added to a stirring solution of azidotrimethylsilane ( $0.07 \mathrm{~g}, 1.2$ equiv.) and 5-bromo2-oxaadamantane 7 ( $0.10 \mathrm{~g}$, in dry DCM $(5 \mathrm{ml})$ under a nitrogen atmosphere at $0{ }^{\circ} \mathrm{C}$. The reaction was stirred at r.t. for $4 \mathrm{~h}$ and then quenched with ice-cold water $(10 \mathrm{ml})$. Extraction with DCM $(3 \times$ $5 \mathrm{ml}$ ) and the combined organic layers were dried over magnesium sulfate, filtered and evaporation of the solvent in vacuo gave a white solid which was purified by sublimation in vacuo (bath temperature $\left.30{ }^{\circ} \mathrm{C}, 10 \mathrm{~mm} \mathrm{Hg}\right)$ to afford 5-azido-2-oxaadamantane $12(0.07 \mathrm{~g}$, $93 \%$ yield) as a pale yellow oil, silica gel TLC $R_{\mathrm{f}} 0.23$ (ethyl acetaten-hexane 70\%); $v_{\max }$ (Neat) $\mathrm{cm}^{-1}, 2933(\mathrm{C}-\mathrm{H}), 2855(\mathrm{C}-\mathrm{H}), 2086$ $\left(\mathrm{N}_{3}\right) ; \delta_{\mathrm{H}}\left(400 \mathrm{MHz}, \mathrm{CDCl}_{3}\right) 1.53-2.65(11 \mathrm{H}, \mathrm{m}), 4.25(2 \mathrm{H}, \mathrm{s}, 1-\mathrm{H}$, $3-\mathrm{H}) ; \delta_{\mathrm{C}}\left(100 \mathrm{MHz}, \mathrm{CDCl}_{3}\right) 27.7,34.5,40.0,40.3$, 59.7 and 69.3; $\mathrm{m} / \mathrm{z}$ (EI) $179\left([\mathrm{M}]^{+}, 7 \%\right), 137$ (100), 93 (100). Found (EI): 179.1055 $[\mathrm{M}]^{+}\left(\mathrm{C}_{9} \mathrm{H}_{13} \mathrm{NO}_{3}\right.$ requires 179.1059).

\section{2-Oxaadamantan-5-ol 13}

5-Bromo-2-oxaadamantane 7 (0.08 g, $1.0 \mathrm{eq})$ was added to silver hexafluoroantimonate $(0.15 \mathrm{~g}, 1.2 \mathrm{eq})$ in liquid sulfur dioxide $(1 \mathrm{ml})$ at $-60{ }^{\circ} \mathrm{C}$ and the reaction was stirred at the same temperature under an argon atmosphere until a change of colour was noticed (usually after 3-5 min). The mixture was then stirred at r.t. until evaporation of sulfur dioxide ceased and was extracted with DCM $(3 \times 15 \mathrm{ml})$. The combined organic layers were dried over magnesium sulfate, filtered and concentrated in vacuo to give 2oxaadamantan-5-ol $\mathbf{1 3}^{\mathbf{2 6 , 2 7}}(0.04 \mathrm{~g}, 70 \%$ yield) as a white solid, which did not require further purification; m.p. $212-214{ }^{\circ} \mathrm{C} ; \delta_{\mathrm{H}}$ $\left(400 \mathrm{MHz}, \mathrm{CDCl}_{3}\right) 1.52\left(2 \mathrm{H}, \mathrm{d}, J 11.7,7-\mathrm{H}_{\mathrm{ax}}, 10-\mathrm{H}_{\mathrm{ax}}\right), 1.71(2 \mathrm{H}$, $\left.J 11.5,4-\mathrm{H}_{\mathrm{ax}}, 6-\mathrm{H}_{\mathrm{ax}}\right), 1.88\left(2 \mathrm{H}, \mathrm{s}, 9-\mathrm{H}_{2}\right), 1.97\left(4 \mathrm{H}, \mathrm{m}, 7-\mathrm{H}_{\mathrm{eq}}, 10-\right.$ $\left.\mathrm{H}_{\mathrm{eq}}, 4-\mathrm{H}_{\mathrm{eq}}, 6-\mathrm{H}_{\mathrm{eq}}\right), 2.34(1 \mathrm{H}, \mathrm{s}, 8 \mathrm{H}), 4.26(2 \mathrm{H}, \mathrm{s}, 1-\mathrm{H}, 3-\mathrm{H}) ; \delta_{\mathrm{C}}$ $\left(100 \mathrm{MHz}, \mathrm{CDCl}_{3}\right)$ 28.5, 34.6, 43.6, 44.2, 67.0 and 70.4.

\section{5-Acetonitrilium-2-oxaadamantane hexafluoroantimonate 14}

5-Bromo-2-oxaadamantane 7 (0.10 g, $1.0 \mathrm{eq})$ and silver hexafluoroantimonate $(0.18 \mathrm{~g}, 1.1 \mathrm{eq})$ were introduced into a dry NMR tube under a stream of dried argon. The NMR tube was sealed with a rubber septum, and the solids kept in vacuo for $10 \mathrm{~min}$ and flushed with argon; this procedure was repeated 5-8 times. Dry acetonitrile $(c a .0 .5 \mathrm{ml})$ was added through a dry cannula, and the NMR tube was sealed and sonicated at r.t. until the formation of a yellow precipitate of $\mathrm{AgBr}$ had ceased (usually $15 \mathrm{~min}$ ). The mixture was centrifuged to settle all the precipitate on the bottom of the tube and then the upper clear solution was transferred through a dry cannula to another dry NMR tube. The solution was centrifuged again to remove remaining residues of $\mathrm{AgBr}$ and transferred again to a dry NMR tube. Solvent was removed in vacuo overnight and then the white solid obtained was suspended in dry dichloromethane and sonicated twice. Finally, elimination of solvent in vacuo for 4-12 h afforded 5-acetonitrilium2-oxaadamantane hexafluoroantimonate 14 (0.12 g, 95\% yield) as a white solid: $\delta_{\mathrm{H}}\left(400 \mathrm{MHz}, \mathrm{CD}_{3} \mathrm{CN}\right) 1.68-1.74\left(9 \mathrm{H}, \mathrm{m}, \mathrm{CH}_{3}\right), 2.10$ $(6 \mathrm{H}, \mathrm{s}), 2.28(3 \mathrm{H}, \mathrm{s}) ; \delta_{\mathrm{C}}\left(100 \mathrm{MHz}, \mathrm{CD}_{3} \mathrm{CN}\right) 21.3,29.7,35.8,40.2$, 59.3 and 176.0 .

\section{5-N-(Acetyl)-2-oxaadamantane 15}

Acetonitrilium-2-oxaadamantane hexafluoroantimonate 14 (0.11 $\mathrm{g}$ ), was added to water and the solvent removed in vacuo to give a white solid residue that was purified by silica gel column chromatography eluting with $70 \% \mathrm{DCM}$ in n-hexane and then $100 \%$ ethyl acetate affording 5- $N$-(acetyl)-2-oxaadamantane 15 $(0.05 \mathrm{~g}, 92 \%$ yield $)$ as a light-brown solid: m.p $119-121{ }^{\circ} \mathrm{C}$; silica gel TLC $R_{\mathrm{f}} 0.40$ (ethyl acetate $\left.100 \%\right) ; v_{\max }$ (Neat) $\mathrm{cm}^{-1}, 3276(\mathrm{~N}-$ $\mathrm{H}), 3077,2928(\mathrm{C}-\mathrm{H}), 1636(\mathrm{C}=\mathrm{O}), 1555 ; \delta_{\mathrm{H}}\left(400 \mathrm{MHz}, \mathrm{CDCl}_{3}\right)$ $1.61\left(2 \mathrm{H}, \mathrm{dd}, J 12.7,3.2,4-\mathrm{H}_{\mathrm{ax}}, 6-\mathrm{H}_{\mathrm{ax}}\right), 1.93\left(3 \mathrm{H}, \mathrm{s}, \mathrm{CH}_{3}\right), 1.99$ $\left(2 \mathrm{H}, \mathrm{d}, J 12.7,4-\mathrm{H}_{\text {eq }}, 6-\mathrm{H}_{\mathrm{eq}}\right), 2.07\left(4 \mathrm{H}, \mathrm{s}, 7-\mathrm{H}_{2}, 10-\mathrm{H}_{2}\right), 2.21(2 \mathrm{H}, \mathrm{s}$, 9- $\left.\mathrm{H}_{2}\right), 2.23(1 \mathrm{H}, \mathrm{s}, 8-\mathrm{H}), 4.18(2 \mathrm{H}, \mathrm{s}, 1-\mathrm{H}, 3-\mathrm{H}), 5.33$ (1H, brs, $\mathrm{N}-\mathrm{H}) ; \delta_{\mathrm{C}}\left(100 \mathrm{MHz}, \mathrm{CDCl}_{3}\right) 24.5\left(\mathrm{CH}_{3}\right), 27.2(\mathrm{C}-8), 34.9\left(\mathrm{C}^{-4}\right.$, C-6), 39.5 (C-9), 40.6 ( C-7 C-10), 50.5 (C-5), 69.1 ( C C $\left.^{-1}, \mathrm{C}-3\right)$ and $169.5(\mathrm{C}=\mathrm{O}) ; m / z(\mathrm{EI}) 195\left([\mathrm{M}]^{+} 63\right), 138(100), 136(42)$ and 92 (42); Found (EI): $195.1261[\mathrm{M}]^{+}\left(\mathrm{C}_{11} \mathrm{H}_{17} \mathrm{NO}_{2}\right.$ requires 195.1259). Scans of the ${ }^{1} \mathrm{H}$ and ${ }^{13} \mathrm{C}$ NMR spectra for this compound are in the ESI. $\dagger$

\section{X-Ray structure determination}

A colorless prism fragment $\left(0.23 \times 0.17 \times 0.04 \mathrm{~mm}^{3}\right)$ was used for the single crystal $\mathrm{X}$-ray diffraction study of $\quad\left[\mathrm{C}_{6} \mathrm{H}_{3} \mathrm{Cl}_{2} \mathrm{C}_{9} \mathrm{H}_{13} \mathrm{OSi}\left(\mathrm{C}_{2} \mathrm{H}_{5}\right)_{3}\right]\left[\mathrm{CHB}_{11} \mathrm{Cl}_{11}\right] \cdot 0.5\left[\mathrm{C}_{6} \mathrm{H}_{4} \mathrm{Cl}_{2}\right] \quad(I D$ cr283_Om). The crystal was coated with paratone oil and mounted on to a cryo-loop glass fiber. X-Ray intensity data were collected at 100(2) $\mathrm{K}$ on a Bruker APEX2 platform-CCD X-ray diffractometer system (Mo-radiation, $\lambda=0.71073 \AA$, $50 \mathrm{kV} / 40$ $\mathrm{mA}$ power). The $\mathrm{CCD}$ detector was placed at a distance of $5.0280 \mathrm{~cm}$ from the crystal. 
A total of 2400 frames were collected for a hemisphere of reflections (with scan width of $0.3^{\circ}$ in $\omega$, starting $\omega$ and $2 \theta$ angles at $-30^{\circ}$, and $\phi$ angles of $0,90,180$ and $270^{\circ}$ for every 600 frames, $30 \mathrm{~s} /$ frame exposure time). The frames were integrated using the Bruker SAINT software package and using a narrow-frame integration algorithm. Based on a monoclinic crystal system, the integrated frames yielded a total of 49229 reflections at a maximum $2 \theta$ angle of $52.74^{\circ}$ ( $0.80 \AA$ resolution), of which 8499 were independent reflections $\left(R_{\mathrm{int}}=0.0745, R_{\mathrm{sig}}=0.0517\right.$, redundancy $=5.8$, completeness $=100 \%)$ and $5893(69.3 \%)$ reflections were greater than $2 \sigma(I)$. The unit cell parameters were, $a=15.1970(5) \AA, b=14.7033(5) \AA, c=19.8581(7) \AA, \beta=$ $110.4569(6)^{\circ}, V=4157.4(2) \AA^{3}, Z=4$, calculated density $D_{\mathrm{c}}=$ $1.588 \mathrm{~g} \mathrm{~cm}^{-3}$. Absorption corrections were applied (absorption coefficient $\mu=0.983 \mathrm{~mm}^{-1} ; \mathrm{max} / \mathrm{min}$ transmission $=0.9617 / 0.8048$ ) to the raw intensity data using the SADABS program.

The Bruker SHELXTL software package (2008) was used for phase determination and structure refinement. The distribution of intensities $(\mathrm{E} 2-1=0.958)$ and systematic absent reflections indicated one possible space group, $P 2_{1} / c$. The space group $P 2_{1} / c$ (\#14) was later determined to be correct. Direct methods of phase determination followed by two Fourier cycles of refinement led to an electron density map from which most of the non-hydrogen atoms were identified in the asymmetry unit of the unit cell. With subsequent isotropic refinement, all of the non-hydrogen atoms were identified. There was one cation of $\left[\mathrm{C}_{9} \mathrm{H}_{13} \mathrm{OC}_{6} \mathrm{H}_{3} \mathrm{Cl}_{2} \mathrm{Si}_{2}\left[\mathrm{C}_{2} \mathrm{H}_{5}\right]_{3}\right]^{+}$, one anion of $\left[\mathrm{CHB}_{11} \mathrm{Cl}_{11}\right]^{-}$, and half a molecule of $\mathrm{C}_{6} \mathrm{H}_{4} \mathrm{Cl}_{2}$ present in the asymmetry unit of the unit cell. The $\mathrm{C}_{6} \mathrm{H}_{4} \mathrm{Cl}_{2}$ solvent was located at the inversion center and modeled as $50 \% / 50 \%$ disordered molecule.

Atomic coordinates, and isotropic and anisotropic displacement parameters of all the non-hydrogen atoms were refined by means of a full matrix least-squares procedure on $\mathrm{F} 2$. The $\mathrm{H}$-atoms were included in the refinement in calculated positions riding on the atoms to which they were attached, except the carborane $\mathrm{CH}$ group (restrained $\mathrm{C}-\mathrm{H}$ distance using DFIX to $0.96 \AA$ ). The refinement converged at $R_{1}=0.0430, \mathrm{w} R_{2}=0.0947$, with intensity $I>2 \sigma(I)$. The largest peak/hole in the final difference map was $0.983 /-0.466 \mathrm{e} / \AA^{3}$.

\section{Calculational methods}

All initial DFT calculations were initially performed using Becke's three-parameter exchange functiona ${ }^{40}$ with the correlation functional of Lee, Yang and Parr (B3LYP). ${ }^{41}$ All species were characterised by full geometry optimization with the standard 6$31 \mathrm{G}(\mathrm{d})$ basis set. Final energies were computed at the mPW1k/6311G(d)//B3LYP/6-31G(d) level. Spin-component-scaled (SCS) MP2 energies were computed as described by Grimme $^{34,35}$ at B3LYP/6-31G(d) geometries. Calculations were performed with the Gaussian $03,^{42}$ Jaguar $^{43}$ or Spartan ${ }^{44}$ program packages. G3MP2 calculations ${ }^{45}$ were carried out with Gaussian 03. Minima and transition states were characterised by analytical frequency calculations.

\section{Acknowledgements}

We are grateful to the EPSRC for funding to FC, and the National Science Foundation for support to CAR. We thank Professor J. N.
Harvey (Bristol) for the G3(MP2) calculations and A. D. Russell for the preparation of 2-oxaadamantan-5-ol.

\section{References}

1 W. C. Zhang, G. S. Viswanathan and C. J. Li, Chem. Commun., 1999, 291-292.

2 D. J. Kopecky and S. D. Rychnovsky, J. Org. Chem., 2000, 65, 191198.

3 D. J. Hart and C. E. Bennett, Org. Lett., 2003, 5, 1499-1502.

4 E. H. Al-Mutairi, S. R. Crosby, J. Darzi, J. R. Harding, R. A. Hughes, C. D. King, T. J. Simpson, R. W. Smith and C. L. Willis, Chem. Commun., 2001, 835-836.

5 K. P. Chan and T. P. Loh, Org. Lett., 2005, 7, 4491-4494.

6 X. Tian, J. J. Jaber and S. D. Rychnovsky, J. Org. Chem., 2006, 71, 3176-3183.

7 S. Marumoto, J. J. Jaber, J. P. Vitale and S. D. Rychnovsky, Org. Lett., 2002, 4, 3919-3922.

8 C. S. Barry, J. D. Elsworth, P. T. Seden, N. Bushby, J. R. Harding, R. W. Alder and C. L. Willis, Org. Lett., 2006, 8, 3319-3322.

9 L. D. M. Lolkema, C. Semeyn, L. Ashek, H. Hiemstra and W. N. Speckamp, Tetrahedron, 1994, 50, 7129-7140.

10 G. Fráter, U. Muller and P. Kraft, Helv. Chim. Acta, 2004, 87, 27502763.

11 S. R. Crosby, J. R. Harding, C. D. King, G. D. Parker and C. L. Willis, Org. Lett., 2002, 4, 577-580.

12 J. J. Jaber, K. Mitsui and S. D. Rychnovsky, J. Org. Chem., 2001, 66, 4679-4686.

13 R. W. Alder, J. N. Harvey and M. T. Oakley, J. Am. Chem. Soc., 2002, 124, 4960-4961.

14 R. Jasti and S. D. Rychnovsky, J. Am. Chem. Soc., 2006, 128, 1364013648.

15 R. Jasti and S. D. Rychnovsky, Org. Lett., 2006, 8, 2175-2178.

16 H. Quast, M. Seefelder, E. M. Peters and K. Peters, Eur. J. Org. Chem., 1999, 1811-1823.

17 D. S. Tarbell and J. R. Hazen, J. Am. Chem. Soc., 1969, 91, 7657-7663.

18 G. A. Olah, Bollinge. Jm, C. A. Cupas and J. Lukas, J. Am. Chem. Soc., 1967, 89, 2692-2694.

19 G. A. Olah, G. K. S. Prakash, J. G. Shih, V. V. Krishnamurthy, G. D. Mateescu, G. Liang, G. Sipos, V. Buss, T. M. Gund and P. V. Schleyer, J. Am. Chem. Soc., 1985, 107, 2764-2772.

20 P. V. Schleyer, W. E. Watts, G. A. Olah, R. C. Fort and Comisaro.Mb, J. Am. Chem. Soc., 1964, 86, 4195-4197.

21 P. R. Schreiner, O. Lauenstein, I. V. Kolomitsyn, S. Nadi and A. A. Fokin, Angew. Chem., Int. Ed., 1998, 37, 1895-1897.

22 P. v. R. Schleyer and R. D. Nicholas, J. Am. Chem. Soc., 1961, 83, 182-187.

23 G. Di Maio, G. Solito, M. R. Vari and E. Vecchi, Tetrahedron, 2000, 56, 7237-7243.

24 P. A. Krasutsky, I. V. Kolomitsin, R. M. Carlson and M. Jones, Tetrahedron Lett., 1996, 37, 5673-5674.

25 P. A. Krasutsky, I. V. Kolomitsyn, P. Kiprof, R. M. Carlson and A. A. Fokin, J. Org. Chem., 2000, 65, 3926-3933.

26 H. Duddeck and P. Wagner, Liebigs Ann. Chem., 1984, 1984, 19811988.

27 N. S. Zefirov, N. V. Averina and O. A. Fomicheva, Khimiya Geterotsiklicheskikh Soedinenii, 1994, 608-612.

28 R. W. Alder, Chem. Ind. (London), 1973, 983-985.

29 T. Kato and C. A. Reed, Angew. Chem., Int. Ed., 2004, 43, 29082911.

30 C. A. Reed, Acc. Chem. Res., 1998, 31, 133-139.

31 D. J. Liston, Y. J. Lee, W. R. Scheidt and C. A. Reed, J. Am. Chem. Soc., 1989, 111, 6643-6648.

32 C. A. Reed, Acc. Chem. Res., 2010, 43, 121-128.

33 B. J. Lynch, P. L. Fast, M. Harris and D. G. Truhlar, J. Phys. Chem. A, 2000, 104, 4811-4815.

34 S. Grimme, J. Phys. Chem. A, 2005, 109, 3067-3077.

35 S. Grimme, J. Chem. Phys., 2003, 118, 9095-9102.

36 T. P. M. Goumans, A. W. Ehlers, K. Lammertsma, E. U. Wurthwein and S. Grimme, Chem.-Eur. J., 2004, 10, 6468-6475.

37 W. C. Still, M. Kahn and A. Mitra, J. Org. Chem., 1978, 43, 29232925.

38 Z. Xie, R. Bau, A. Benesi and C. A. Reed, Organometallics, 1995, 14, 3933-3941. 
39 H. Suginome and S. Yamada, Tetrahedron Lett., 1984, 25, 39953998.

40 A. D. Becke, J. Chem. Phys., 1993, 98, 5648-5652.

41 C. T. Lee, W. T. Yang and R. G. Parr, Phys. Rev. B: Condens. Matter, 1988, 37, 785-789.

42 G. W. M. J. T. Frisch, H. B. Schlegel, G. E. Scuseria, M. A. Robb, J. R. Cheeseman, J. A. Montgomery, Jr., T. Vreven, K. N. Kudin, J. C. Burant, J. M. Millam, S. S. Iyengar, J. Tomasi, V. Barone, B. Mennucci, M. Cossi, G. Scalmani, N. Rega, G. A. Petersson, H. Nakatsuji, M. Hada, M. Ehara, K. Toyota, R. Fukuda, J. Hasegawa, M. Ishida, T. Nakajima, Y. Honda, O. Kitao, H. Nakai, M. Klene, X. Li, J. E. Knox, H. P. Hratchian, J. B. Cross, V. Bakken, C. Adamo, J. Jaramillo, R. Gomperts, R. E. Stratmann, O. Yazyev, A. J. Austin, R. Cammi, C. Pomelli, J. W. Ochterski, P. Y. Ayala, K. Morokuma, G. A. Voth,
P. Salvador, J. J. Dannenberg, V. G. Zakrzewski, S. Dapprich, A. D. Daniels, M. C. Strain, O. Farkas, D. K. Malick, A. D. Rabuck, K. Raghavachari, J. B. Foresman, J. V. Ortiz, Q. Cui, A. G. Baboul, S. Clifford, J. Cioslowski, B. B. Stefanov, G. Liu, A. Liashenko, P. Piskorz, I. Komaromi, R. L. Martin, D. J. Fox, T. Keith, M. A. Al-Laham, C. Y. Peng, A. Nanayakkara, M. Challacombe, P. M. W. Gill, B. Johnson, W. Chen, M. W. Wong, C. Gonzalez and J. A. Pople, Gaussian, Inc., Wallingford CT, 2004, Gaussian 03, 2004.

43 7.0.113, Maestro Version 7.0.113, Schrödinger, L. L. C., New York, 1999-2005.

44 I. Wavefunction, Spartan '06, Wavefunction, Inc, Irvine, CA, USA, Spartan '06 edn, 2006.

45 L. A. Curtiss, P. C. Redfern, K. Raghavachari, V. Rassolov and J. A. Pople, J. Chem. Phys., 1999, 110, 4703-4709. 